\title{
부호화된 $\mathrm{MIMO}$ 시스템에서 $\mathrm{QR}$ 분해를 이용한 효율적인 연판정 검출
}

장 매 향, 김 수 영

\section{Soft Detection using QR Decomposition for Coded MIMO System}

\author{
Meixiang Zhang, Sooyoung Kim \\ 요 약
}

무선통신시스템에서의 고용량 데이터 전송을 위해 MIMO 전송은 필수적인 기술의 하나로 자리매김하였다. 더 불어 열악한 채널환경에서 요구되는 성능을 만족하기 위해서는 반드시 고효율 오류정정부호를 사용하여야하며, 반 복적인 복호 기법을 사용하는 터보부호나 저밀도 패리티 검사부호 등이 그 예라고 할 수 있다. 이러한 오류정정 부호들의 우수한 성능은 반드시 MIMO 검출 단에서의 정확한 연판정 검출 값이 전제되어야 한다. 본 논문에서는 매우 적은 복잡도로 효과적으로 연판정 검출 값을 복호기에 전달 할 수 있는 방법으로써 채널 행렬의 $\mathrm{QR}$ 분해 기법을 적용한 연판정 검출 기법을 제안한다. 본 논문에서 제안하는 방식은 먼저 연판정 MIMO 검출 단계를 두 단계로 나누어 복잡도를 획기적으로 감소시킬 수 있는 방법과 결합하였으며, 채널 행렬에 대하여 직접 역행렬을 구하는 방식에 비해서 안테나 수가 증가할수록 훨씬 더 적은 복잡도로 동일한 성능을 얻을 수 있다.

Key Words : Multi-Input Multi-Output (MIMO), soft decision detection, turbo codes, ZF;QR.

\section{ABSTRACT}

Multi-Input Multi-Output (MIMO) transmission is now considered as one of essential techniques enabling high rate data transmissions in wireless communication systems. In addition, severe channel impairments in wireless systems should be compensated by using highly efficient forward error correction (FEC) codes. Turbo codes or low density parity check (LDPC) codes, using iterative decoding with soft decision detection information (SDDI), are the most common examples. The excellent performance of these codes should be conditioned on accurate estimation of SDDI from the MIMO detection process. In this paper, we propose a soft MIMO detection scheme using QR decomposition of channel matrices as an efficient means to provide accurate SDDI to the iterative decoder. The proposed method employed a two sequential soft MIMO detection process in order to reduce computational complexity. Compared to the soft ZF method calculating the direct inverse of the channel matrix, the complexity of the proposed method can be further reduced as the number of antennas is increased, without any performance degradation.

\section{I. 서 론}

다중 안테나 방식(multi-input multi-output;
MIMO)은 현대 무선통신시스템에서 고용량의 데이 터 전송을 위하여 반드시 요구되는 기술의 하나이 다. 이처럼 $\mathrm{MIMO}$ 전송을 채택하고 있는 시스템에

※ 이 논문은 2009년도 정부(교육과학기술부)의 재원으로 한국연구재단의 지원을 받아 수행된 기초연구사업임(No. 2009-0088286)

- 주저자 : 전북대학교 전자공학부 IT 융합연구센터, mei1986xiang@live.cn, 준회원

○ 교신저자 : 전북대학교 전자공학부 IT 융합연구센터, sookim@jbnu.ac.kr, 종신회원

논문번호 : KICS2012-03-118, 접수일자 : 2012년 3월 12일, 최종논문접수일자 : 2012년 6월 11일 
서는 채널에서 발생하는 여러 가지 열화조건을 극 복하기 위해서는 보다 강력한 오류정정 부호화 능 력을 가지고 있는 오류 정정(forward error correction; FEC) 부호를 결합하여 채택하고 있다 [1,2]. 이와 같은 FEC 방식의 대표적인 예가 터보부 호나 저밀도 패리티 검사(low density parity check; LDPC) 부호 등이라고 할 수 있다 ${ }^{[3,4]}$. 이러한 부호 들의 특징은 부호기에 제공되는 연판정 입력 값을 사용하여 반복적으로 복호를 수행함으로써 높은 성 능을 도출하는 것으로써, 이를 위해서는 반드시 정 확한 연판정 값의 계산이 전제되어야 한다.

따라서 대부분의 무선통신시스템은 MIMO 방식 과 터보부호나 LDPC 부호와 같은 반복 복호를 사 용하는 $\mathrm{FEC}$ 방식을 결합하여 사용할 것이며, 이 경 우 $\mathrm{MIMO}$ 신호의 검출 후에 수행되는 반복 복호 과정에서는 정확한 연판정 입력 값이 필요하게 된 다. 이 연판정 입력 값의 신뢰도가 복호 성능에 큰 영향을 미치기 때문에 효율적으로 연판정 검출 값 을 출력할 수 있는 MIMO 신호 검출 방식의 필요 성이 매우 크다고 할 수 있다 ${ }^{[5]}$.

가장 정확하게 $\mathrm{MIMO}$ 검출 값을 계산하여 최대의 성능을 얻기 위해서는 최대 우도 검출 (maximum likelihood detection; MLD) 방법을 사용해야 한다 ${ }^{[6]}$. 그러나, 이 방법은 사용되는 전송 안테나 수와 변조 차수에 따라 그 계산 복잡도가 지수적으로 증가하기 때문에 실제 시스템에서의 구현은 거의 불가능하다. 반면에 가장 복잡도가 적은 검출 방식으로는 zero forcing 검출 (ZFD) 방법을 들 수 있으나, 검출 과정 에서 발생하는 잡음 증가(noise enhancing) 현상으로 인한 성능 저하가 가장 큰 문제점으로 지적되고 있다. 이제까지 제안되어온 여러 가지 MIMO 검출 방식들 은 $\mathrm{MLD}$ 의 복잡도를 개선하면서도 $\mathrm{ZFD}$ 의 성능 열화 를 보상할 수 있는 방향으로 초점이 맞추어져 왔다. 그러나, 많은 방식들은 여전히 전수 조사를 기본으로 하는 $\mathrm{MLD}$ 에서 조사하는 방식들의 횟수를 줄이는 방 식들을 그 기본 개념으로 하고 있다 ${ }^{[6,7]}$.

위와 같은 점을 고려하여, 선행연구인 참고논문 [4]에서는 시공간블럭부호화(space-time block coding; STBC) 및 공간 다중화(spatial multiplexing; SM) 기반의 MIMO 방식의 검출 시 연판정 비트 값을 어떻게 추출해야 하는지의 과정 을 수식으로 상세히 유도하는 방법을 제시한 바 있 다. 이 방식의 핵심은 연판정 검출 과정을 두 단계 로 분할함으로써, MIMO 검출 단계를 별도로 분리 하고 사후에 연판정비트 검출 과정에 적절한 채널
이득을 반영하는 것이다 ${ }^{[8,9]}$. 이렇게 하면 지수적으 로 그 복잡도가 증가하는 연판정 MLD 과정 대신 에 복잡도가 단지 선형적으로 증가하도록 할 수 있 다.

본 논문에서는 이러한 개념을 연속적으로 사용하 여, 선형 검출 방식을 사용하는 MIMO 시스템에서 연판정 $\mathrm{MIMO}$ 검출 과정을 두 단계로 나누어 적은 복잡도로 정확한 연판정 검출 값을 추출하는 방법 을 제시한다. 본 논문에서 제시된 방식은 채널 행렬 의 $\mathrm{QR}$ 분해를 이용하여 $\mathrm{ZFD}$ 를 적용한 방식과 성 능은 동일하면서도 더 적은 복잡도를 가지는 방식 이다.

본 서론에 이어 II장에서는 연판정 검출 방법의 기본 개념에 대하여 알아보고, III장에서는 채널 행 렬의 $\mathrm{QR}$ 분해 과정에 대한 유도를 통하여 $\mathrm{QR}$ 분 해를 이용한 연판정 검출의 원리를 제시하고 최소 복잡도로 구현할 수 있는 알고리즘을 제시한다. IV 장에서는 제안된 알고리즘을 포함한 여러 가지 연 판정 검출 방식에 대한 터보 부호와 고차원 변조 방식을 연계한 $\mathrm{MIMO}$ 방식의 성능을 알아보고 $\mathrm{V}$ 장에서 결론을 맺는다.

\section{II. 선형 연판정 $\mathrm{MIMO}$ 검출 방법}

\section{1. 시스템 모델}

그림 1 에는 $N$ 개의 송신 안테나와 $M$ 개의 수신 안테나를 구비하고, 반복 복호기를 사용하는 부호화 된 $\mathrm{MIMO}$ 시스템의 구성도가 나타나 있다. 이와 같은 시스템을 통하여 수신된 신호 벡터는 아래 식 (1)과 같이 나타낼 수 있다.

$$
\mathrm{r}=H \mathrm{~s}+\mathrm{n},
$$

여기서, $\mathrm{s}$ 는 크기가 $N \times 1$ 인 변조 심볼 벡터이 고 $\mathrm{y}$ 와 $\mathrm{n}$ 은 각각 크기가 $M \times 1$ 인 수신 신호 벡터 와 잡음 벡터 이다. $\mathrm{n}$ 의 원소들은 서로 독립적이며 동일하게 분포된 분산 값이 $\sigma^{2}$ 인 복소 가우시안 (Gaussian) 랜덤 변수이다. $H$ 는 식 (2)로 표현될 수 있는 $M \times N$ 복소 채널 행렬이다.

$$
H=\left[\begin{array}{cccc}
h_{11} & h_{12} & \cdots & h_{1 N} \\
h_{21} & h_{22} & \cdots & h_{2 N} \\
\vdots & \vdots & \ddots & \vdots \\
h_{M 1} & h_{M 2} & \cdots & h_{M N}
\end{array}\right]
$$


여기서, $h_{i j}$ 는 $j$ 번째 전송 안테나로부터 $i$ 번째 수신 안테나까지에 해당하는 경로의 채널 이득이다. 수신신호 백터 $\mathrm{r}$ 이 수신되면, MIMO 검출기는 반 복 복호기에서 사용할 수 있도록 연판정 정보를 검 출하여야 한다. 이와 같은 연판정 $\mathrm{MIMO}$ 검출은 복잡도와 성능을 고려하여 여러 가지 방법으로 수 행할 수 있으며, 아래 절에서는 여러 가지의 연판정 $\mathrm{MIMO}$ 검출 방법에 대하여 살펴보기로 한다.

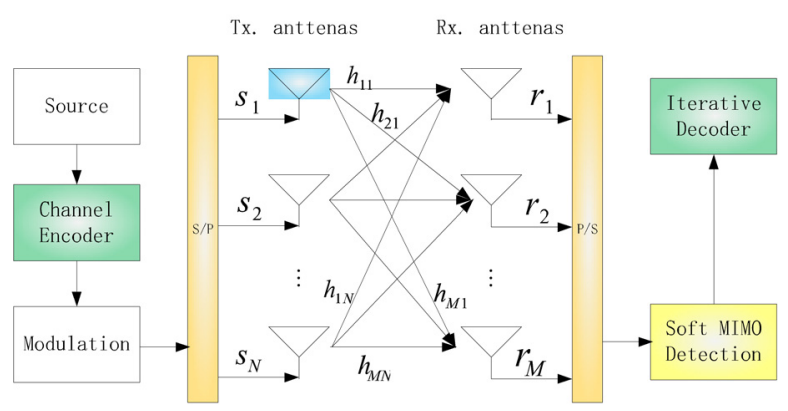

그림 1. 연판정 정보를 사용하여 반복 복호하는 방식의 $\mathrm{MIMO}$ 전송 시스템 모델

Fig. 1. System model for a coded MIMO system using iterative soft decoding

\subsection{MLD MIMO 검출 기법}

$\mathrm{MIMO}$ 검출기에서 반복 복호기에 제공되는 연판 정 정보는 아래 식과 같이 MLD 미터릭을 사용하 는 로그 확률값 (log likelihood ratio; LLR)을 사용 하여 계산할 수 있다 ${ }^{[5]}$.

$L\left(b_{i} \mid \mathrm{r}\right)=\log \left(\frac{\sum_{\mathrm{S}: b_{i}(\mathrm{~s})=1} \exp \left(-\frac{1}{2 \sigma^{2}}\|\mathrm{r}-H \mathrm{~s}\|^{2}\right)}{\sum_{\mathrm{S}: b_{i}(\mathrm{~s})=0} \exp \left(-\frac{1}{2 \sigma^{2}}\|\mathrm{r}-H \mathrm{~s}\|^{2}\right)}\right)$

여기서, $\mathrm{s}$ 는 송신 심볼 백터로써, 그림 1을 참조하면 $N$ 개의 송신 안테나에서 전송되는 $N$ 개의 심볼로 구 성되며, 각 심볼들은 다시 $m$ 개의 비트로 구성되어 있 다. 따라서, 벡터 $\mathrm{s}$ 는 총 $m N$ 개의 비트 $b_{i}$ 로 구성되 며, $\mathrm{S}$ 는 $m N$ 개의 비트로 구성할 수 있는 비트 조합들 의 집합이다. 이 MLD 방법은 최대 우도의 성능을 거 둘 수 있지만 식 (3)의 계산 복잡도가 $m N$ 지수 배로 증가되는 단점을 가지고 있다.

위 (3)의 LLR 값을 계산함에 있어서 지수 연산과 로그 연산의 성질을 활용하면, 전체 심볼 조합에 대한 모든 거리 값의 지수 값을 더하는 대신에 식 (4)와 같 이 그 중에 최대 값만을 취함으로써 복잡도를 다소 감 소시킬 수 있는 Max Log 미터릭 값을 사용할 수 있
다. 그러나, 이 역시도 최소 값을 찾는 전수조사 횟수 자체가 안테나 수와 변조 차수에 대해 지수적으로 증 가하기 때문에 복잡도는 여전히 매우 크다고 할 수 있 다.

$$
\begin{aligned}
& L\left(b_{i} \mid \mathbf{r}\right) \approx \log \left(\frac{\max _{\mathrm{S}: b_{i}(\mathrm{~s})=1} \exp \left(-\frac{1}{2 \sigma^{2}}\|\mathrm{r}-H \mathrm{~s}\|^{2}\right)}{\max _{\mathrm{S}: b_{i}(\mathbf{s})=0} \exp \left(-\frac{1}{2 \sigma^{2}}\|\mathrm{r}-H \boldsymbol{s}\|^{2}\right)}\right) \\
& \approx \frac{1}{2 \sigma^{2}}\left(\min _{\mathrm{S}: b_{i}(\mathrm{~s})=0}\|\mathrm{r}-H \mathrm{~s}\|^{2}-\min _{\mathrm{S}: b_{i}(\mathrm{~s})=1}\|\mathrm{r}-H \mathbf{s}\|^{2}\right) .
\end{aligned}
$$

위 식에서 \|\| 는 임의의 복소 벡터에 대한 크 기(norm)를 계산하는 연산자이다. 따라서, $\|\mathrm{r}-H \mathrm{~s}\|$ 는 수신 백터와 송신 가능한 심볼 백터 와의 거리 계산 연산을 의미한다.

\section{3. 선형 연판정 $\mathrm{MIMO}$ 검출 기법}

위에서 기술된 MLD 방법은 가장 정확하게 연판 정 비트 값을 계산할 수 있으나, 그 복잡도가 매우 커 안테나 수나 변조 차수가 높아지게 되면 실제로 사용이 거의 불가능하게 된다. 이러한 단점을 보완 하기 위하여 연판정 비트 검출을 두단계로 분할하 여 수행하는 방법이 제안되었는데, 먼저 MIMO 심 볼 검출을 수행한 후 심볼 내에 포함되어 있는 연 판정 비트 정보를 분리해 내는 방법이다 ${ }^{[5]}$. 본 절에 서는 $\mathrm{MIMO}$ 신호 검출 방법 중 선형 계산 방법에 대해 간단히 살펴보기로 한다.

$\mathrm{ZFD}$ 는 수신된 신호에 채널 매트릭스의 역을 곱 함으로써, 송신된 신호를 검출하는 방법을 말한다. 그러므로 $\mathrm{ZFD}$ 를 사용하여 검출된 신호 백터 $\hat{\mathrm{s}}$ 은 아래 식 (5)로 표현할 수 있다.

$$
\hat{\mathrm{s}}=H^{-1} \mathrm{r}=\mathrm{s}+H^{-1} \mathrm{n} .
$$

위 식 (5)에서 $H^{-1}$ 는 복소 채널행렬 $H$ 의 역행렬이 며, 식 (5)를 사용하여 검출된 신호 백터 $\hat{\mathrm{s}}$ 은 심볼 단 계의 값들이므로 심볼을 구성하고 있는 비트 단위의 정보를 추출하는 추가 작업이 필요하다.

각 검출된 심볼 안에 들어있는 연 판정 비트 값은 간단한 선형 계산만으로 계산될 수 있다. 즉, $b_{k}^{i}$ 를 $i$ 번 째 심볼 $\widehat{s_{i}}$ 를 구성하고 있는 $k$ 번째 비트에 대한 연판 정 값이라고 할 때, $\hat{b_{k}^{i}}$ 는 아래 식 (6)과 같이 $\hat{s_{i}}$ 가 $k$ 번 째 비트에 대한 경판정 검출 경계 값과 이루는 거리에 
가중치를 곱하여 계산할 수 있다다.

$$
\widehat{b_{k}^{i}}=\alpha_{i}\left(\frac{2}{\sigma^{2}} b_{k}^{i}\right) \text {, }
$$

여기서, $b_{k}^{i}$ 는 $\hat{s_{i}}$ 가 $k$ 번째 비트에 대한 경판정 검출 경 계 값과 이루는 거리이다. 이와 같이 각 심볼을 구성 하고 있는 비트에 대한 연판정 값을 추출하는 방법에 대한 보다 상세한 내용은 참고문헌 [5]를 참조할 수 있다. 그리고 $\alpha_{i}$ 는 ZFD 단계에서 변화된 잡음의 분산 값을 보정해 주기 위한 가중치로써, 아래 식 (7)과 같 이 계산될 수 있다.

$$
\alpha_{i}=\frac{1}{\sum_{j=1}^{N}\left\|h_{i j}^{\prime}\right\|},
$$

여기서 $h^{\prime}{ }_{i j}$ 는 $H^{-1}$ 의 $i$ 번째 행, $j$ 번째 열의 값이다. 최소평균제곱오차 (minimum mean squared estimation; MMSE) 검출 방법은 평균 제곱오차를 최 소화 시키는 적당한 행렬 $G$ 를 찾기 위한 선형 검출 방법이다. MMSE 검출 방법을 통해서 검출된 신호 $\hat{\mathrm{s}}$ 는 아래 식 (8)로 표현할 수 있다 ${ }^{[9]}$.

여기서,

$$
\hat{\mathrm{s}}=G \mathrm{r},
$$

$$
G=\left(H^{H} H+\sigma^{2} I\right)^{-1} H^{H} .
$$

위 식 (9)에서 $H^{H}$ 는 복소 채널행렬 $H$ 의 헤르미안 (Hermitian)이다. 식 (8)을 이용한 심볼 단계의 검출 작업이 완료되면, $\mathrm{ZFD}$ 에서와 동일한 방법으로 각 심 볼을 구성하고 있는 비트에 대한 연판정 정보 $b_{k}^{i}$ 를 계 산할 수 있다. MMSE 검출 시 발생하는 잡음 분산의 변화는 ZFD에서와는 다를 것이므로, MMSE 검출 시 가중치 $\alpha_{i}$ 는 다음 식 (10)으로 나타낼 수 있다 ${ }^{[9]}$.

$$
\alpha_{i}=\frac{1}{\sum_{k=1}^{M}\left\|h_{k i}\right\|^{2}+\sigma^{2}}-\sigma^{2}
$$

\section{QR 분해를 이용한 연 판정 $\mathrm{MIMO}$ 검출}

\section{1. 개요}

이제까지 기술된 부호화 시스템에서의 연판정 정보 검출 방법에 바탕을 두고 본 장에서는 채널 행렬 $H$ 에
대한 $\mathrm{QR}$ 분해 기법을 적용하여 복잡도를 추가로 감 소 시킬 수 있는 방법에 대하여 기술한다. 먼저 아래 2절에서는 채널 행렬 $H$ 에 대한 $\mathrm{QR}$ 분해 기법의 기본 개념과 이를 이용하여 MIMO 신호 검출을 수행하는 과정에 대하여 기술한다. 또, 3절에서는 이러한 내용 을 바탕으로 복잡도를 최소화하여 신호를 검출할 수 있는 방법과 연판정 비트를 검출할 수 있는 방법을 기 술한다.

\section{2. 채널 행렬의 $\mathrm{QR}$ 분해}

행렬 $H$ 의 $\mathrm{QR}$ 분해이란 $H$ 가 전열계수(full column rank) 행렬이라는 가정 하에 직교 행렬인 $Q$ 와 상삼각 (upper triangular) 행렬인 $R$ 의 곱으로 분해하는 것이 다. 본 절에서는 Gram-Schmidt 프로세스를 통하여 $H$ 의 $\mathrm{QR}$ 분해 과정을 살펴보고, 그 결과를 $\mathrm{MIMO}$ 검출 에 사용할 수 있음을 기술한다. 이와 같은 방법으로 신호를 검출하게 되면 $\mathrm{ZFD}$ 를 이용한 방법보다 더 적 은 복잡도로 신호를 검출할 수 있게 된다.

행렬 $H$ 의 $i$ 번째 열 백터를 $\mathrm{h}_{i}, i \in\{1,2, \cdots N\}$ 로 표 시하면 $H=\left[\mathrm{h}_{1} \mathrm{~h}_{2} \cdots \mathrm{h}_{N}\right]$ 로 쓸 수 있다. 또, 백터 $\mathrm{h}$ 에 대한 백터 e 방향으로의 직교 영사 (orthogonal projection) 성분은 아래 식 (11)로 나타낼 수 있다.

$$
\operatorname{proj}_{\mathrm{e}} \mathrm{h}=\frac{\mathrm{e} \cdot \mathrm{h}}{\|\mathrm{e}\|^{2}} \mathrm{e} .
$$

먼저, 행렬 $Q$ 를 아래 식 (12)로 나타내 보자.

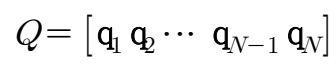

여기서, $\mathrm{q}_{1}, \mathrm{q}_{2}, \cdots, \mathrm{q}_{N}$ 은 행렬 $Q$ 의 열백터들로써 아래 식 (13)으로 표현할 수 있다.

$$
\mathrm{q}_{i}=\frac{\mathrm{u}_{i}}{\left\|\mathrm{u}_{i}\right\|},
$$

그리고

$\mathrm{u}_{i}=\left\{\begin{array}{l}\mathrm{h}_{i}, \\ \mathrm{~h}_{i}-\sum_{j=1}^{i} \operatorname{proj}_{\mathrm{q}_{\mathrm{i}}}, i \in\{2,3, \cdots N\},\end{array}\right.$

따라서, 행렬 $R$ 은 아래 식 (15)과 같이 표현할 수 있 다. 


$$
R=Q^{H} H=\left[\begin{array}{cccc}
r_{11} & r_{12} & \cdots & r_{1 N} \\
0 & r_{22} & \cdots & r_{2 N} \\
\vdots & \vdots & \ddots & \vdots \\
0 & 0 & \cdots & r_{N N}
\end{array}\right]
$$

이와 같은 개념을 바탕으로 하여 $\mathrm{MIMO}$ 신호 검출 에 $\mathrm{QR}$ 분해 결과를 사용하기로 한다. 신호를 검출하 기 위해서 수식 (1)의 양변에 $Q^{H}$ 을 곱해주면 아래 식 (16)과 같이 표현할 수 있다.

$$
\mathrm{y}=Q^{H} \mathrm{r}=R \mathbf{s}+Q^{H} \mathrm{n}
$$

행렬 $R$ 은 식 (15)에서 알 수 있는 바와 같이 상삼각 행렬이기 때문에 $N$ 번째 행에는 마지막 열에 하나의 값 $r_{N N}$ 만 존재한다. 따라서 $\hat{s}_{N}$ 은 간단하게 식 (17) 과 같이 계산할 수 있다.

$$
\widehat{s_{N}}=\frac{y_{N}}{r_{N N}}=s_{N}+\frac{\mathrm{q}_{N}^{H} \mathrm{n}}{r_{N N}} .
$$

그러나 $i$ 가 $N$ 보다 적은 $\hat{s}_{i}$ 를 계산할 때는 다른 열의 성분들이 존재하기 때문에, 식 (18)에 나타나 있는 바 와 같이 $\hat{s}_{k}, k>i$ 신호로 부터의 간섭 성분이 존재한 다.

$$
\hat{s}_{i}=\frac{y_{i}}{r_{i i}}-\frac{\sum_{j=i+1}^{N} r_{i j} s_{j}}{r_{i i}}, j \neq N .
$$

식 (18)에서 $s_{j}$ 들 $(i<j \leq N)$ 에 대한 참 값은 존재하 지 않기 때문에 $s_{j}$ 들을 사용하여 $\hat{s}_{i}$ 를 검출하는 것은 $i$ 가 작을수록 간섭으로 인한 오차가 커지게 된다.

채널 행렬 $H$ 에 대하여 열 백터의 순서를 변경한 행 렬 $H^{(2)}=\left[\mathrm{h}_{1} \mathrm{~h}_{2} \cdots \mathrm{h}_{N} \mathrm{~h}_{N-1}\right]$ 로 정의하여 $H^{(2)}$ 에 대 하여 $\mathrm{QR}$ 분해한 결과를 $Q^{(2)}=\left[\mathrm{q}_{1} \mathrm{q}_{2} \cdots \mathrm{q}_{N}^{(2)} \mathrm{q}_{N-1}^{(2)}\right]$ 라 고 하자. 이제 $Q^{(2)}$ 에 대한 $R^{(2)}$ 에는의 마지막 행에 는 $\hat{s}_{N-1}$ 에 해당하는 값만이 존재하기 때문에 다른 신호에 대한 간섭 없이 계산할 수 있다. 즉, 식 (19)를 통해서 $\hat{s}_{N-1}$ 을 얻을 수 있다.

$$
\hat{s}_{N-1}=\frac{y_{N-1}^{\prime}}{r_{(N-1)(N-1)}^{(2)}}=s_{N-1}+\frac{\left(\mathrm{q}_{N-1}^{(2)}\right)^{H} \mathrm{n}}{r_{(N-1)(N-1)}^{(2)}}
$$

따라서, 이와 같이 해당하는 성분에 대한 검출 값을 간섭 없이 얻기 위하여 채널 행렬의 열 백터의 순서를 변경하여 $\mathrm{QR}$ 분해를 하게 되면, $\hat{s}_{N}$ 부터 $\hat{s}_{1}$ 까지 모든
신호를 간섭 없이 검출할 수 있다.

\section{3. $\mathrm{QR}$ 분해를 이용한 연판정 검출}

이제 위에서 설명한 원리를 적용하여 $\mathrm{MIMO}$ 신호 를 저 복잡도로 검출하기 위하여, $\mathrm{QR}$ 분해를 좀 더 자세히 분석해 보기로 하자. $\mathrm{QR}$ 분해 과정으로 부터 식 (20)을 쓸 수 있다.

$$
\mathrm{q}_{i} \cdot \mathrm{h}_{i}=\left\{\begin{array}{l}
r_{N N,} i=N \\
0, \quad i \neq N
\end{array}\right.
$$

또, 위 식 (20)의 결과를 바탕으로 아래 식 (21)이 성 립될 수 있도록 매트릭스 $Q$ 를 구성하게 되면, $R^{\prime}=Q^{\prime} H$ 는 대각 행렬이 되어 모든 신호들에 대해 다른 신호들에 대한 간섭 없이 신호 검출이 가능하게 된다.

$$
\mathrm{q}_{j}^{\prime} \cdot \mathrm{h}_{i=}\left\{\begin{array}{l}
r_{i i}, i=j, \\
0, i \neq j,
\end{array}\right.
$$

$Q^{\prime}$ 에 대한 유도를 위하여 먼저, 행렬 $H$ 의 열백터들 의 순서를 변경한 행렬 $H^{(i)}, i \in\{1,2, \cdots, N\}$ 를 아래 식 (22)와 같이 정의하기로 한다.

$$
\begin{aligned}
& H^{(1)}=\left[\mathrm{h}_{1} \mathrm{~h}_{2} \cdots \mathrm{h}_{N-2} \mathrm{~h}_{N-1} \mathrm{~h}_{N}\right], \\
& H^{(2)}=\left[\mathrm{h}_{1} \mathrm{~h}_{2} \cdots \mathrm{h}_{N-2} \mathrm{~h}_{N} \mathrm{~h}_{N-1}\right] \text {, } \\
& \dot{H}^{(i)}=\left[\mathrm{h}_{1} \mathrm{~h}_{2} \cdots \mathrm{h}_{N-i} \mathrm{~h}_{N-i+2} \cdots \mathrm{h}_{N} \mathrm{~h}_{N-i+1}\right], \\
& \dot{H}^{(N)}=\left[\mathrm{h}_{2} \mathrm{~h}_{3} \cdots \mathrm{h}_{N-1} \mathrm{~h}_{N} \mathrm{~h}_{1}\right] \text {. }
\end{aligned}
$$

또, 각 $H^{(i)}$ 에 대한 $\mathrm{QR}$ 분해한 결과 행렬 $Q^{(i)}$ 는 식 (23)으로 표현할 수 있을 것이다.

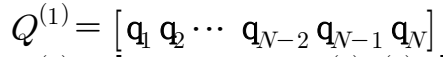

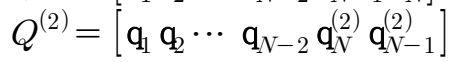

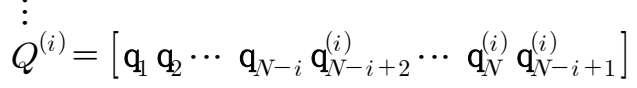

$$
\begin{aligned}
& \dot{Q}^{(N)}=\left[\mathrm{q}_{2}^{(N)} \mathrm{q}_{3}^{(N)} \cdots \mathrm{q}_{N-1}^{(N)} \mathrm{q}_{N}^{(N)} \mathrm{q}_{1}^{(N)}\right]
\end{aligned}
$$

여기서 $\mathrm{q}_{N}^{(1)}=\mathrm{q}_{N}$ 이 된다. 그리고,

$$
\begin{gathered}
\mathrm{q}_{j}^{(i)}=\frac{\mathrm{u}_{j}^{(i)}}{\left\|\mathrm{u}_{j}^{(i)}\right\|}, \\
\mathrm{u}_{j}^{(i)}=\mathrm{h}_{j}-\mathrm{C}_{j}^{(i)}-\mathrm{V}_{j}^{(i)},
\end{gathered}
$$




$$
\begin{gathered}
\mathrm{C}_{j}^{(i)}=\sum_{\mathrm{k}=1}^{\mathrm{N}-\mathrm{i}} \operatorname{proj}_{\mathbf{q}_{\mathrm{k}}} \mathrm{h}_{\mathrm{j}}, \\
\mathrm{V}_{j}^{(i)}=\left\{\begin{array}{l}
\sum_{k=N-i+2}^{j-1} \operatorname{proj}_{\mathbf{q}_{k}^{(i)}} \mathbf{h}_{j}, j \neq N-i+1, \\
\sum_{k=N-i+2}^{N} \operatorname{proj}_{\mathbf{q}_{k}^{(i)}} \mathbf{h}_{j}, j=N-i+1 .
\end{array}\right.
\end{gathered}
$$

이와 같은 과정을 통하여 모든 $H^{(i)}$ 와 $Q^{(i)}$ 를 저장 및 계산하기 위해서는 총 $N$ 배의 기억 장치가 필요하 고 $N$ 배의 $\mathrm{QR}$ 분해 과정이 필요한 것으로 보일 수 있 다. 그러나, 실제로는 이보다 훨씬 더 적은 연산으로 도 필요한 결과를 얻을 수 있다.

즉, 이전 $\mathrm{QR}$ 분해 결과들을 이용하고, $Q^{(i)}$ 에 해당 하는 갱신된 백터들 $\left(\mathrm{q}_{N-i+j}^{(i)}, j \in\{1,2, \cdots, i\}\right)$ 만 갱신하 면 되는데, 그 개수는 $N(N+1) / 2$ 이다. 그림 2는 행 렬 $H$ 에 대한 초기 $\mathrm{QR}$ 분해 결과인 $Q$ 를 바탕으로 제 안된 방식으로 $Q$ 와 $R^{\prime}$ 을 계산하는 알고리즘을 정리 한 것이다. 이해를 돕기 위하여 부록에서는 $4 \times 4$ 채널 행렬을 이용한 계산 과정을 예시로 제시하였다.

이제 이 결과들을 이용하여 식 (21)을 만족하는 해 $Q$ 은 아래 식과 같이 나타낼 수 있다.

$$
Q=\left[\mathrm{q}_{1}^{(N)} \cdots \mathrm{q}_{N+1-i}^{(i)} \cdots \mathrm{q}_{N-2}^{(3)} \mathrm{q}_{N-1}^{(2)} \mathrm{q}_{N}^{(1)}\right] .
$$

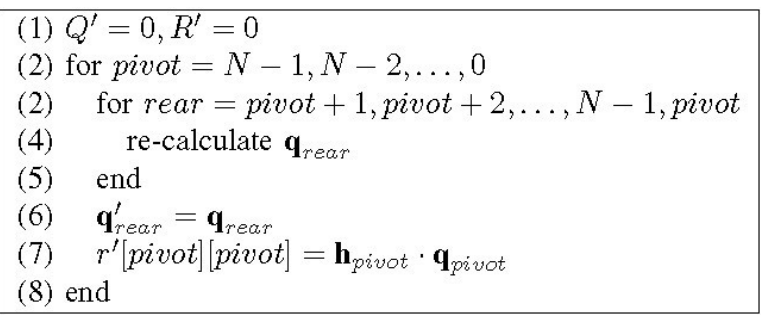

그림 2. $Q$ 를 바탕으로 $Q^{\prime}$ 과 $R^{\prime}$ 을 계산하는 알고리즘

Fig. 2. Algorithm to calculate $Q^{\prime}$ and $R^{\prime}$ based on $Q$

또, $R^{\prime}$ 은 식 (29)과 같이 표현할 수 있다.

$$
R^{\prime}=\left(Q^{\prime}\right){ }^{H} H=\left[\begin{array}{cccc}
r_{11}^{\prime} & 0 & \cdots & 0 \\
0 & r_{22}^{\prime} & \cdots & 0 \\
\vdots & \vdots & r^{\prime} & 0 \\
0 & 0 & \cdots & r_{N N}^{\prime}
\end{array}\right] \text {. }
$$

위의 $Q$ 과 $R^{\prime}$ 을 이용하여 $\mathrm{MIMO}$ 검출 결과를 나타 내면 아래 식 (30)과 같이 정리할 수 있다.

$$
\begin{aligned}
& \mathbf{y}=\left(Q^{\prime}\right)^{H} \mathbf{r}=\left(Q^{\prime}\right)^{H}(H \mathbf{s}+\mathbf{n}) \\
& =\left(Q^{\prime}\right)^{H} H \mathrm{~s}+\mathrm{n}^{\prime} \\
& =R^{\prime} \mathrm{s}+\mathrm{n}^{\prime} \\
& =\left[\begin{array}{cccc}
r^{\prime}{ }_{11} & 0 & \cdots & 0 \\
0 & r_{22}^{\prime} & \cdots & 0 \\
\vdots & \vdots & r^{\prime} & 0 \\
0 & 0 & \cdots & r_{N N}^{\prime}
\end{array}\right]\left[\begin{array}{c}
s_{1} \\
s_{2} \\
\vdots \\
s_{N}
\end{array}\right]+\left[\begin{array}{c}
n^{\prime}{ }_{1} \\
n^{\prime}{ }_{2} \\
\vdots \\
n^{\prime}
\end{array}\right],
\end{aligned}
$$

여기서 $\mathrm{n}^{\prime}=\left(Q^{\prime}\right)^{H} \mathrm{n}$. 따라서

$$
\widehat{s_{i}}=\frac{y_{i}}{r_{i i}^{\prime}}=s_{i}+\eta_{i,}^{\prime} i \in\{1,2, \cdots, N\}
$$

이며

$$
\eta_{i}^{\prime}=\frac{n_{i}^{\prime}}{r_{i i}^{\prime}}=\frac{\left(q_{i}^{\prime}\right)^{H_{\mathrm{n}}}}{r_{i i}^{\prime}}
$$

또한 심볼 $\widehat{s_{i}}$ 에 포함되어 있는 각 비트에 대한 연판정 값은 식 (6)을 통하여 계산할 수 있다. 또한, 제안된 $\mathrm{QR}$ 분해를 이용한 방법에서의 잡음 분산의 변화를 고려하면, 가중치 값은 아래와 같이 표현될 수 있다.

$$
\begin{aligned}
\alpha_{i} & =\frac{E\left[\left(n_{i}\right)^{2}\right]}{E\left[\left(\eta_{i}^{\prime}\right)^{2}\right]} \\
& =\frac{\sigma^{2}}{\left\|\frac{\left(\mathrm{q}_{i}^{\prime}\right)^{H}}{r_{i i}^{\prime}}\right\|^{2} \sigma^{2}}=\left\|\frac{r_{i i}^{\prime}}{\left(\mathrm{q}_{i}^{\prime}\right)^{H}}\right\|^{2} .
\end{aligned}
$$

\section{IV. 모의 실험 결과}

본 장에서는 채널 행렬에 대한 $\mathrm{QR}$ 분해를 사용하 여 복잡도를 감소시킨 연 판정 $\mathrm{MIMO}$ 검출 방법에 대한 비트오류율(bit error rate; BER) 성능 시뮬레이 션 결과를 기존의 여러 가지 다른 연 판정 검출 방법 들과 비교한다. BER 성능 시뮬레이션을 위하여 오류 정정부호화방법으로는 와이브로 규격에 정의된 듀오 바이너리 터보부호를 사용하였으며, 터보부호의 프레 임 길이는 192 심볼 (398비트)이며 부호화율은 $1 / 3$ 이 다 ${ }^{[2]}$. 터보부호에 대한 반복 복호 알고리즘으로는 Max-log-MAP 알고리즘을 사용하였으며, 최대 반복 횟수는 8 회로 제한하였다. 또 16-QAM 변조 방식을 사용하는 $2 \times 2$ 및 $4 \times 4 \mathrm{MIMO}$ 방식을 가정하였으 며, 각 MIMO 프레임별로 독립적인 페이딩 변수가 발 생하는 레일레이 페이딩 채널을 사용하였다. 


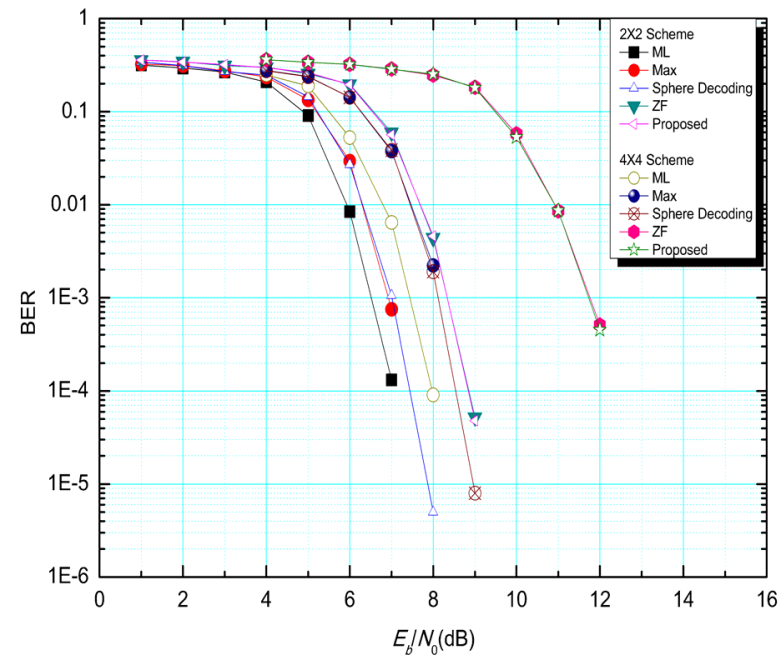

그림 3. 여러 가지 연판정 $\mathrm{MIMO}$ 검출 기법의 $\mathrm{BER}$ 성능 시뮬레이션 결과

Fig. 3. BER performance results of various soft MIMO detection schemes

그림 3의 여러 가지 연판정 MIMO 검출 방식에 대 한 $\mathrm{BER}$ 성능 시뮬레이션 결과를 살펴보면, $\mathrm{QR}$ 분 해를 이용한 제안된 기법은 연판정 ZFD와 동일한 성 능을 얻을 수 있음을 알 수 있다. 또 MLD 방식 및 Max MLD 방식에 비해서는 안테나 수에 따라 약 2-3 $\mathrm{dB}$ 의 성능 저하가 있음을 알 수 있다. 또 성능 및 복 잡도 측면에서의 상대적인 비교를 위하여 그림 3 에는 연판정 MIMO 검출 기법의 또 다른 한 방법인 sphere 복호 (sphere decoding; SD) 방법에 대한 성능이 같이 나타나 있다. 이 SD 방법은 채널 행렬의 값을 고려하 여, MLD에서 요구하는 전수 조사의 계산양을 줄이는 일종의 복잡도 감소 연판정 $\mathrm{MIMO}$ 검출 방식이다 [7,10,11]

비록 제안된 방식을 이용할 경우 어느 정도의 성능 저하를 감수하여야 한다고 하더라도 복잡도 감소 측 면에서는 엄청난 이득을 얻을 수 있다. 이러한 복잡도 측면에서의 비교를 위하여 표 1에는 그림 3에 나타나 있는 여러 가지 연판정 $\mathrm{MIMO}$ 검출 기법에 대한 복 잡도를 연판정 비트 정보 계산에 필요한 연산의 수를 비교하여 나타내었다. 아래 표 1의 \| $\|^{2}$ 연산은 수 식 (3)과 (4)의 $\left\|\mathrm{r}-H_{\mathrm{s}}\right\|^{2}$ 을 의미한다.
표 1. 여러 가지 연판정 $\mathrm{MIMO}$ 검출 기법들에 대한 복잡도 비교

Table 1. Complexity comparision of various soft MIMO detection schemes

\begin{tabular}{|c|c|c|c|c|c|}
\hline $\begin{array}{r}\text { 연산 } \\
\text { 검출 방법 }\end{array}$ & + & $\times$ & $\exp ()$ & $\log ()$ & \|\|$^{2}$ \\
\hline $\mathrm{MLD}$ & 0 & 0 & $2^{m N}$ & $N$ & $2^{m N}$ \\
\hline $\mathrm{MAX}$ & 0 & 0 & 0 & & $2^{m N}$ \\
\hline $\mathrm{SD}$ & 0 & 0 & 0 & 0 & $\frac{1+N}{2 N} 2^{m N}$ \\
\hline $\mathrm{ZFD}$ & $N_{Z a}$ & $N_{Z m}$ & 0 & 0 & $m N$ \\
\hline Proposed & $N_{p}$ & $N_{p}$ & 0 & 0 & $m N$ \\
\hline
\end{tabular}

연산의 횟수를 계산하기 위하여 ZFD에 사용되는 복소 채널의 역행열 계산 방식으로 식 (34)의 연산 방 식을 사용하였다 ${ }^{[7]}$.

$$
\begin{aligned}
H^{-1} & =(A+i B)^{-1} \\
& =\left(A+B A^{-1} B\right)^{-1}-i A^{-1} B\left(A+B A^{-1} B\right)^{-1},
\end{aligned}
$$

여기서 $A$ 와 $B$ 는 각각 복소 행렬 $H$ 의 실수 및 허수 부에 해당하는 행렬이다. 또 이와 같은 복소 행렬의 역행렬 계산법을 이용할 경우 $\mathrm{ZFD}$ 에서 필요한 덧셈 의 횟수 $N_{Z a}$ 와 곱셈의 횟수 $N_{Z m}$ 은 아래 식 (35)와 (36)로 정리할 수 있다.

$$
\begin{gathered}
N_{Z a}=2(N+1) !+3 N^{3}+2 N^{2}, \\
N_{Z m}=2(N+1) !+3 N^{3} .
\end{gathered}
$$

또, 제안된 $\mathrm{QR}$ 분해를 이용한 연판정 MIMO 방식의 경우 요구되는 덧셈 및 곱셈의 수는 $N_{p}$ 로 동일하며, 아래 식 (37)과 같이 정리할 수 있다.

$$
N_{p}=\frac{2 N^{4}+6 N^{3}+7 N^{2}}{3}
$$

표 1에서 나타나 있는 바와 같이 ZFD와 제안된 방 식의 경우 가장 많은 연산이 필요한 거리 연산 ( $\left.\|\quad\|^{2}\right)$ 에 소요되는 연산의 수가 단지 $m N($ 변조 차 수 $\times$ 송신 안테나 수) 만큼만 소요되기 때문에, 지수적 으로 그 계산량이 증가하게 되는 다른 방식들에 비해 엄청난 계산양 감소를 가져올 수 있음을 알 수 있다. 아래 그림 4는 여러 가지 연판정 MIMO 검출 방법에 서 필요로 하는 복소 거리 계산 횟수를 비교하여 나타 낸 것으로써, $\mathrm{ZFD}$ 와 제안된 방식의 경우 선형 증가 
를 나타내기 때문에 엄청난 양의 감소 효과가 있음을 알 수 있다.

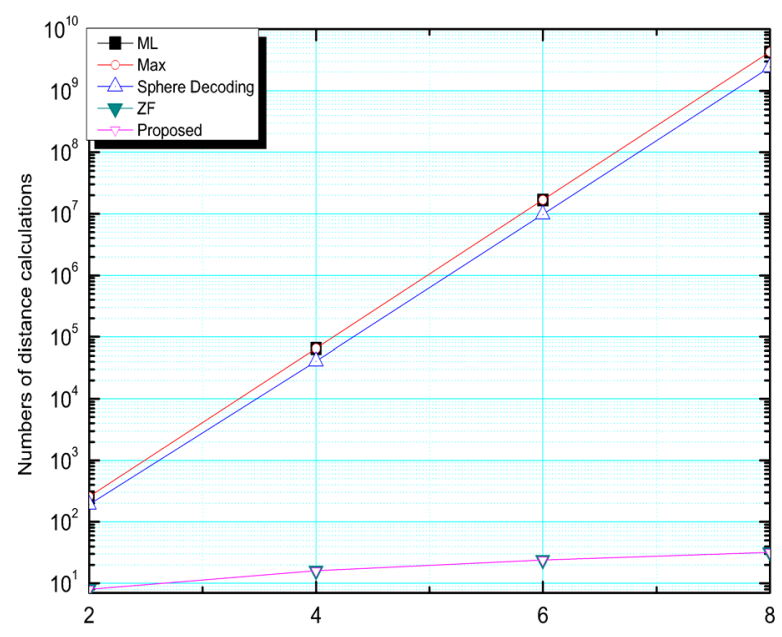

그림 4. 여러 가지 연판정 MIMO 검출 방법에서 필요로 하는 거리 계산 수의 비교

Fig. 4. Number of distance estimations required in various soft MIMO detection schemes

또한, 그림 5와 그림 6은 ZFD와 제안된 방식에서 의 송신 안테나의 개수 $N$ 에 따른 BER 성능 그래프 및 필요로 하는 덧셈 및 곱셈의 횟수를 비교하여 나타 낸 것으로써, 제안된 방식의 경우 $\mathrm{BER}$ 성능은 $\mathrm{ZFD}$ 와 동일하면서도 송신 안테나의 개수 $N$ 이 증가하면 할수 록 이득이 더 크게 나타남을 알 수 있다. 예를 들어 송 신 안테나의 개수가 2-4일 경우 그 계산 이득이 약 $10 \%$ 에 불과하지만 안테나 개수가 8개를 늘어나게 되 면 계산 횟수가 약 $1 / 1000$ 로 감소하게 됨을 알 수 있 다.

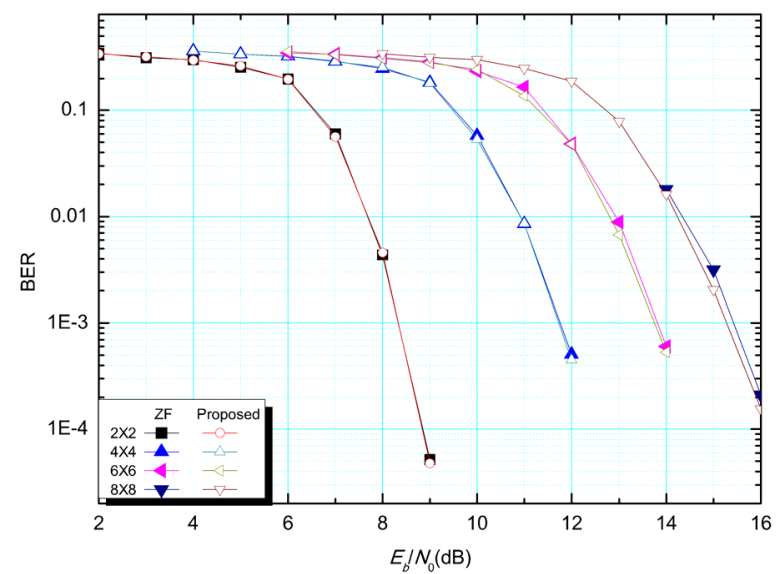

그림 5. ZFD 및 제안된 검출 방법에서의 안테나 수 증가에 따른 $\mathrm{BER}$ 성능

Fig. 5. Comparison of BER performances of the ZFD and proposed scheme according to the number of antennas.

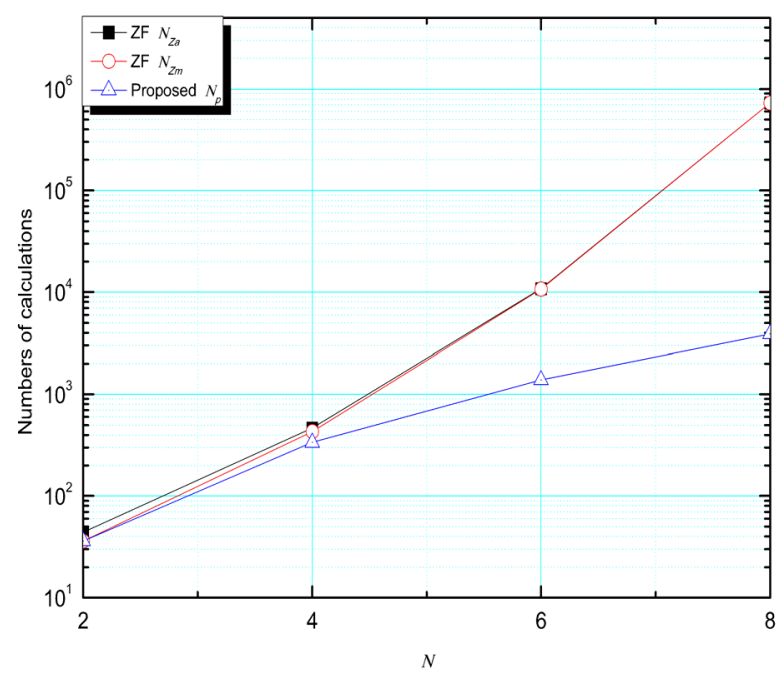

그림 6. $\mathrm{ZFD}$ 및 제안된 검출 방법에서의 곱셈 및 덧셈 연 산수의 비교

Fig. 6. Comparison of the number of additions and multiplications required in the ZFD and proposed scheme.

\section{V. 결 론}

본 논문에서는 연판정 정보를 이용하여 반복적으 로 복호를 수행하여 성능을 향상시킬 수 있는 오류 정정부호화 방식을 $\mathrm{MIMO}$ 시스템에서 사용할 경우 효과적인 연판정 $\mathrm{MIMO}$ 검출방식을 제안하였다. 본 논문에서 제안된 방식은 채널 행렬에 대한 $\mathrm{QR}$ 분 해 기법을 적용함으로써 매우 복잡도가 적은 알고 리즘을 사용하여 구현하였다. 또한, 심볼 단계의 $\mathrm{MIMO}$ 신호를 검출 한 뒤 각 심볼 신호에 포함된 연판정 정보를 분리하고 적절한 가중치를 곱해줌으 로써 효과적으로 오류정정부호와 결합하여 우수한 성능을 낼 수 있도록 하였다. 본 논문에서 제안된 방식은 송신 안테나 및 변조 차수가 높아질수록 그 복잡도 감소 효과가 더 뛰어난 방식이다.

\section{참 고 문 헌}

[1] "3rd Generation Partnership Project; Technical Specification Group Radio Access Network; Evolved Universal Terrestrial Radio Access (E-UTRA); Physical Channels and Modulation (Release 8)," 3GPP TS 36.211 V8.3.0 (2008-05)

[2] IEEE 802.16 Standard - Local and Metropolitan Area Networks - Part 16, IEEE Std 802. 163-2005.

[3] C. Berrou, A. Glavieux, and P. Thitimajshima, 
"Near Shannon limit error-correcting coding and decoding: Turbo-codes," Proc. of IEEE Int. Conf. Commun., Geneva, Switzerland, pp. 1064-1070, 1993.

[4] T. J. Richardson, M. A. Shokrollahi, and R. L. Urbanke, "Design of Capacity-Approaching Irregular Low-Density Parity-Check Codes," IEEE Trans. Inf. Theory, 47(2), pp. 619-637, Feb. 2001.

[5] 김영민, 상평평, 김수영, “부호화된. $\mathrm{MIMO}$ 시 스템에서 연판정 채널 이득값의 계산," 한국통 신학회논문지, 36(6), pp. 577-586, Jun. 2011.

Youngmin Kim, Pingping Shang, and Sooyoung Kim, "Estimation of soft deicion channel gain for coded MIMO system," The Journal of the Korean Institute of Communication Sciences, 36(6), pp. 577-586, Jun. 2011

[6] Erik G. Larsson and Joakim Jalden "Fixed-complexity soft MIMO detection via partial marginalization," IEEE Trans. Commun., 56(8), pp. 3397-3407, Aug. 2008

[7] L. G. Barbero and J. S. Thompson, "A fixed-complexity MIMO detector based on the complex sphere decoder," IEEE Signal Process. Advanced Wireless Commun (SPAWC), Cannes, France, Jul. 2006.

[8] P. Shang, S. Kim, and K. Choi, "Soft ZF MIMO detection for turbo codes," Proc. of 6th Wireless and Mobile Computing, Networking and Communications, Niagara Falls, Canada, pp. 116-120, 2010.

[9] P. Shang, S. Kim, and K. Choi, "Soft MMSE receiver for turbo coded MIMO system," Proc. of 4th Workshop on Selected Topics in Mobile and Wireless Computing, Shanghai, China, pp. 471-475, 2011.

[10] C. Studer, A. Burg, and H. Bolcskei, "Soft-output sphere decoding: algorithms and VLSI implementation," IEEE J. Select. Areas in Commun., 26(2), pp. 290-300, Feb. 2008.

[11] J. Joakim and B. Ottersten, "Parallel Implementation of a Soft Output Sphere Decoder," Proc. of Signals, Systems and Computers, Pacific Grove, USA, pp. 581-585, 2005.

\section{Appendix}

본 부록에서는 본문에서 제시된 채널 행렬의 $\mathrm{QR}$ 분해를 이용하여 $\mathrm{MIMO}$ 신호를 검출하는 과정을 $4 \times 4$ 채널 행렬을 이용하여 그 예를 제시한다. 먼저 채널 행렬 $H$ 를 아래와 같이 나타내자.

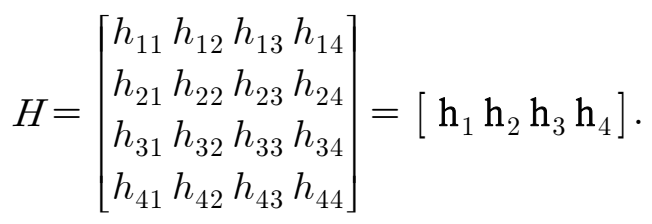

또, 위 $H$ 에 대하여 $\mathrm{QR}$ 분해 과정을 수행하여 얻은 행 렬 $\mathrm{Q}$ 가 아래와 같이 나타난다고 하자.

$$
Q=\left[\begin{array}{llll}
q_{11} & q_{12} & q_{13} & q_{14} \\
q_{21} & q_{22} & q_{23} & q_{24} \\
q_{31} & q_{32} & q_{33} & q_{34} \\
q_{41} & q_{42} & q_{43} & q_{44}
\end{array}\right]=\left[\begin{array}{lll}
\mathrm{q}_{1} & \mathrm{q}_{2} & \mathrm{q}_{3} \\
\mathrm{q}_{4}
\end{array}\right] .
$$

위 (A.1)의 채널 행렬 $H$ 에 대하여 각 열들의 순서만 재배열한 행렬 $H^{(i)}, i \in\{1,2,3,4\}$ 는 아래와 같이 나타 낼 수 있다.

$$
\begin{aligned}
H^{(1)} & =\left[\mathrm{h}_{1} \mathrm{~h}_{2} \mathrm{~h}_{3} \mathrm{~h}_{4}\right]=H, \\
H^{(2)} & =\left[\mathrm{h}_{1} \mathrm{~h}_{2} \mathrm{~h}_{4} \mathrm{~h}_{3}\right], \\
H^{(3)} & =\left[\mathrm{h}_{1} \mathrm{~h}_{3} \mathrm{~h}_{4} \mathrm{~h}_{2}\right], \\
H^{(4)} & =\left[\mathrm{h}_{2} \mathrm{~h}_{3} \mathrm{~h}_{4} h_{1}\right],
\end{aligned}
$$

여기서 위 각 $H^{(i)}$ 에는 $\mathrm{H}$ 의 각 열들의 순서만 변경한 것으로써 별도의 계산은 필요 없으며, 수식의 유도를 위하여 표기한 것이다. 이제 위 식 (A.3)의 각 $H^{(i)}$ 에 대한 $\mathrm{QR}$ 분해 결과인 행렬 $Q^{(i)}$ 는 순차적으로 아래 와 같이 구할 수 있다. 먼저 $H^{(1)}$ 에 대한 $Q^{(1)}$ 은 $H^{(1)}$ 이 $H$ 와 동일하므로 아래와 같이 (A.2)의 $\mathrm{Q}$ 와 동일하 다. 즉,

$$
Q^{(1)}=\left[\begin{array}{llll}
\mathrm{q}_{1} & \mathrm{q}_{2} & \mathrm{q}_{3} & \mathrm{q}_{4}^{(1)}
\end{array}\right],
$$

여기서 $Q^{(1)}=Q$ 이므로, $\mathrm{q}_{4}^{(1)}=\mathrm{q}_{4}$ 이다. 또, $H^{(2)}$ 는 $H^{(1)}$ 과 비교하여 세 번째 열과 네 번째 열 의 순서만 바뀌었고 첫 번째 열과 두 번째 열의 순 서는 동일하므로, $Q^{(2)}$ 의 첫 번째 열과 두 번째 열 
역시 $Q^{(1)}$ 과 동일하고 첫 번째 열과 두 번째 열의 값을 이용하여 세 번째 열과 네 번째 열의 값만 구 하면 된다. 즉,

$$
Q^{(2)}=\left[\begin{array}{llll}
\mathrm{q}_{1} & \mathrm{q}_{2} & \mathrm{q}_{4}^{(2)} & \mathrm{q}_{3}^{(2)}
\end{array}\right]
$$

여기서, $\mathrm{q}_{3}^{(2)}$ 와 $\mathrm{q}_{4}^{(2)}$ 는 각각 $\mathrm{q}_{i}^{(2)}=\mathrm{u}_{i}^{(2)} /\left\|\mathrm{u}_{i}^{(2)}\right\|$ 로 표현되는 값으로서, $\mathrm{h}_{3}$ 와 $\mathrm{h}_{4}$ 로부터 아래와 같 이 계산될 수 있다. 즉,

$$
\begin{gathered}
\mathrm{u}_{4}^{(2)}=\mathrm{h}_{4}-\operatorname{proj}_{\mathrm{q}_{1}} \mathrm{~h}_{4}-\operatorname{proj}_{\mathrm{q}_{2}} \mathrm{~h}_{4}, \\
\mathrm{u}_{3}^{(2)}=\mathrm{h}_{3}-\operatorname{proj}_{\mathrm{q}_{1}} \mathrm{~h}_{3}-\operatorname{proj}_{\mathrm{q}_{2}} \mathrm{~h}_{3}-\operatorname{proj}_{\mathrm{q}_{4}^{(2)}} \mathrm{h}_{3} .
\end{gathered}
$$

이와 같은 동일한 원리를 이용하여, $H^{(3)}$ 에 대한 $Q^{(3)}$ 를 다음과 같이 구할 수 있다. 즉,

$$
Q^{(3)}=\left[\begin{array}{llll}
\mathrm{q}_{1} & \mathrm{q}_{3}^{(3)} & \mathrm{q}_{4}^{(3)} & \mathrm{q}_{2}^{(3)}
\end{array}\right],
$$

여기서 $\mathrm{q}_{i}^{(3)}=\mathrm{u}_{i}^{(3)} /\left\|\mathrm{u}_{i}^{(3)}\right\|$ 이며,

$$
\begin{gathered}
\mathrm{u}_{3}^{(3)}=\mathrm{h}_{3}-\operatorname{proj}_{\mathrm{q}_{1}} \mathrm{~h}_{3}, \\
\mathrm{u}_{4}^{(3)}=\mathrm{h}_{4}-\operatorname{proj}_{\mathrm{q}_{1}} \mathrm{~h}_{4}-\operatorname{proj}_{\mathrm{q}_{3}^{(3)}} \mathrm{h}_{4}, \\
\mathrm{u}_{2}^{(3)}=\mathrm{h}_{2}-\operatorname{proj}_{\mathrm{q}_{1}} \mathrm{~h}_{2}-\operatorname{proj}_{\mathrm{q}_{3}^{(3)}} \mathrm{h}_{2}-\operatorname{proj}_{\mathrm{q}_{4}} \mathrm{~h}_{2} .
\end{gathered}
$$

또한, $H^{(4)}$ 에 대한 $Q^{(4)}$ 도 다음과 같이 구할 수 있다. 즉,

$$
Q^{(4)}=\left[\mathrm{q}_{2}^{(4)} \mathrm{q}_{3}^{(4)} \mathrm{q}_{4}^{(4)} \mathrm{q}_{1}^{(4)}\right]
$$

$$
\text { 여기서 } \mathrm{q}_{i}^{(4)}=\mathrm{u}_{i}^{(4)} /\left\|\mathrm{u}_{i}^{(4)}\right\| \text { 이며, }
$$

$$
\begin{aligned}
& \mathrm{u}_{2}^{(4)}=\mathrm{q}_{2}^{(4)}, \\
& \mathrm{u}_{3}^{(4)}=\mathrm{h}_{3}-\operatorname{proj}_{\mathrm{q}_{2}^{(4)}} \mathrm{h}_{3}, \\
& \mathrm{u}_{4}^{(4)}=\mathrm{h}_{4}-\operatorname{proj}_{\mathrm{q}_{2}^{(4}} \mathrm{h}_{4}-\operatorname{proj}_{\mathrm{q}_{3}^{(4)}} \mathrm{h}_{4}, \\
& \mathrm{u}_{1}^{(4)}=\mathrm{h}_{1}-\operatorname{proj}_{\mathrm{q}_{2}^{(4)}} \mathrm{h}_{1}-\operatorname{proj}_{\mathrm{q}_{3}^{(4)}} \mathrm{h}_{1}-\operatorname{proj}_{\mathrm{q}_{4}^{(4)}} \mathrm{h}_{1} \text {. }
\end{aligned}
$$

이제 이 결과들을 이용하여 식 (21)을 만족하 는 해 $Q^{\prime}$ 은 아래 식과 같이 나타낼 수 있다.

$$
Q^{\prime}=\left[\mathrm{q}_{1}^{(4)} \mathrm{q}_{2}^{(3)} \mathrm{q}_{3}^{(2)} \mathrm{q}_{4}^{(1)}\right]
$$

또, $\mathrm{QR}$ 분해된 행렬 $\mathrm{Q}$ 의 성질을 이용하면 식 (29)의 $R^{\prime}$ 은 대각 행렬이 되고, 대각 성분 값은 아래 식으로 나타낼 수 있다.

$$
\begin{aligned}
& r_{11}^{\prime}=\mathrm{q}_{1}^{(4)} \cdot \mathrm{h}_{1}, \\
& r_{22}^{\prime}=\mathrm{q}_{2}^{(3)} \cdot \mathrm{h}_{2}, \\
& r_{33}^{\prime}=\mathrm{q}_{3}^{(2)} \cdot \mathrm{h}_{3}, \\
& r_{44}^{\prime}=\mathrm{q}_{1}^{(1)} \cdot \mathrm{h}_{4} .
\end{aligned}
$$

\section{장 매 향 (Meixiang Zhang)}

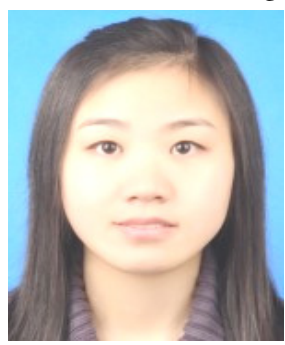

2009년 7월 중남민족대학교 컴퓨터공학 학사

2010년 9월 현재 전북대학교 전자공학 석사 과정 중

<관심분야>

터보부호 coded MIMO, 위성통신

\section{김 수 영 (Sooyoung Kim)}

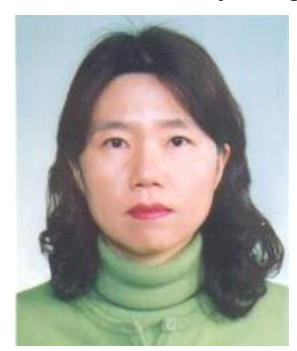

1990년 2월 한국과학기술원 전 기 및 전자공학과 학사

1990년 2월 1991년 9월 ETRI 연구원

1992년 10월 Univ. of Surrey, U.K 공학석사

1995년 2월 Univ. of Surrey,

U.K 공학박사

1994년 11월 1996년 6월 Research Fellow, Univ. of Surrey, U.K

1996년 8월 2004년 2월 ETRI 광대역무선전송연구 팀장

2004년 3월 현재 전북대학교 전자공학부 부교수 <관심분야> 오류정정부호화방식, coded $\mathrm{MMO}$, 이 동/위성통신 